\title{
NO ATUAL CONTEXTO EDUCACIONAL A IMPORTÂNCIA DA UNIDADE DE NOVOS NEGÓCIOS
}

\author{
Gleicione Aparecida Dias Bagne de SOUZA ${ }^{1}$
}

Recebido em: 15/04/2015 - Aprovado em: 05/06/2015 - Disponibilizado em: 15/07/2015

\begin{abstract}
RESUMO: Este artigo aponta a importância da elaboração de uma Unidade de Novos Negócios para a Universidade Vale do Rio Verde - UninCor. Esta deve adotar em seu portfólio cursos de extensão, cursos técnicos, pesquisas, consultoria e demais atividades. Será mais um diferencial em relação as Instituições de Ensino concorrentes. Para isso será necessário reinventar a organização corporativa. A Unidade de Novos Negócios deverá caminhar junto com as propostas pedagógicas da UninCor, ou seja, de acordo com os documentos institucionais, como PDI e PPI; será um "negócio educacional", porém integrado e agregado aos Cursos. A proposta apresentada, não se vale de unificação dos setores, mas sim de integração dos mesmos, integrar não é unificar, mas novas conexões entre diferentes setores/grupos.
\end{abstract}

Palavras chave: Negócio. Extensão. Pesquisa. Responsabilidade Social. Ensino Superior.

ABSTRACT: This article points the importance of creating Business Development Area at the Universidade Vale do Rio Verde - UninCor. The University must adopt extention courses, techinician, researches, consulting and other activities. This will be a differential in comparison to its competitors. For this to happen, it will be necessary to reinvent the corporative organization. The "Business Development Area" must work according to the educational proposals suggested by the University and the institutional documents, such as the "Institutional Development Plan" and "Institutional Educational Plan". This new area is not about a unification of sectors, but a integration, connecting them to create a more collaborative and effective environment.

Key words: Business. Extension. Research. Social responsibility. Tertiary education

${ }^{1}$ Doutora em Desenvolvimento Curricular. Reitora e Pró-reitora de Graduação e Assuntos Acadêmicos.
E-mail: gleici@unincor.edu.br 


\section{INTRODUÇÃO}

A Unidade de Novos Negócios deve apoiar em um dos pilares da missão da UninCor "Promover e disseminar o conhecimento com responsabilidade em suas áreas de atuação, formando profissionais de alta qualidade, aptos para o mercado de trabalho e comprometidos com a vida, ética, sociedade e o meio ambiente".

A proposta deste artigo é a integração do setor de extensão, pesquisa e responsabilidade social nesta Unidade de Negócio. Sabe-se que a extensão é uma ponte de relação entre o discente e a comunidade, possibilitando a constante busca do equilíbrio entre as demandas socialmente exigidas e as inovações acadêmicas. Desta forma, os cursos oferecidos/trabalhados com a comunidade empresarial poderão envolver também os discentes. Muitos alunos da UninCor já trabalham nas empresas ou estagiam, desta forma, ficará mais viável a realização de parceria das empresas com a Unidade de Novos Negócios. Essa integração permitirá também contabilizar cursos de extensão nas áreas de conhecimento dos diversos cursos de graduação da UninCor, além do envolvimento da comunidade acadêmica.
A extensão integrada na Unidade de Novos Negócios será um diferencial para a UninCor, pois poderá abranger ainda mais sua área de atuação, aumentar significativamente as possibilidades de parcerias e conexão do aluno com o mercado de trabalho.

Em relação ao setor pesquisa, vale lembrar que "para o aluno aprender, tem de pesquisar, não só para produzir conhecimento próprio, mas principalmente para se formar de maneira adequada. Pesquisar não se reduz a conhecimento de ponta, mas é, antes de tudo, ambiente de aprendizagem" (DEMO, 2005, p.78).

Com a integração entre a Unidade de Novos Negócios e pesquisa o aluno através do Projeto Interdisciplinar - PIN poderá elaborar pesquisa em parceria com o setor empresarial. Ele contará com o apoio dos docentes nas orientações da pesquisa, e consequentemente no artigo, fazendo ponte relacional entre a teoria estudada e a prática vivenciada. A pesquisa permitirá ao aluno a evolução em relação ao saber pensar, fundamentar, argumentar, questionar, de forma a construir/reconstruir seu conhecimento. "Dar aula" não implica necessariamente ser uma atividade de aprendizagem, pois os professores poderão somente repassar conteúdos 
curriculares e depois aplicarem provas. Esta proposta de integração entre a pesquisa e a Unidade de Novos Negócios possibilitará ao aluno infiltrar na empresa/organização e construir seu aprendizado através da pesquisa, da comparação, constatação, verificação e outros.

Neste contexto, a instituição estará também trabalhando o aluno para um melhor desempenho nas avaliações do ENADE e concursos, pois “conhecimento precisa ser 'feito', não apenas escutado e reproduzido" (DEMO, 2005, p. 27).

A UninCor receberá recursos das empresas/organizações para a realização da pesquisa. Esta proposta de trabalho visa também o oferecimento de cursos técnicos em parcerias com as empresas. É possível oferecer cursos técnicos concomitantes e sequenciais para trabalhadores das empresas e comunidade, porém alocados em escolas de Ensino Médio².

2 A Fundação Comunitária Tricordiana de Educação já possui o Colégio de Aplicação, o que viabiliza o oferecimento desses cursos.

\section{QUE DIFERENCIAL TERIA A UNIDADE DE NOVOS NEGÓCIOS?}

A Unidade de Novos Negócios trabalhará de forma unificada com as atividades de extensão, pesquisa e responsabilidade social, buscando parcerias entre a comunidade acadêmica e empresas/organizações, aumentando a visibilidade da UninCor diante da comunidade interna e externa.

Com as novas políticas governamentais será necessário buscar novos caminhos financeiros para a instituição. Receber recursos das empresas/organizações através das atividades de extensão, pesquisa e responsabilidade social, além de possibilitar a instituição cumprir sua missão, melhorar a qualidade da educação e responder aos futuros desafios e oportunidades, é uma excelente oportunidade.

Em relação ao pedagógico da instituição, esta Unidade de Gestão irá intensificar a pesquisa através da integração entre Iniciação Científica e empresas/organizações parceiras.

Oferecerá as empresas/organizações parceiras atividades de extensão através de palestra, seminários, consultorias, cursos, pesquisa e outros. Irá integrar os 
diversos discentes e docentes nesses projetos.

Possibilitará o fortalecimento das atividades de extensão através das parcerias e oportunizará ao aluno a vivência prática da teoria trabalhada em sala de aula.

O aluno contará com um aprendizado mais efetivo, contribuindo em sua formação profissional e consequentemente nos resultados do ENADE e concursos. Será também oportunizado através do PIN, a pesquisa e a elaboração do artigo, onde intensificará publicações de artigos, melhorando o índice de publicações dos docentes; atingindo a exigência do Instrumento de Avaliação do MEC/INEP, além de receber recursos financeiros das empresas para realização desta.

Será também possível aumentar a conexão dos alunos da UninCor ao mercado de trabalho será um diferencial, pois aumentar rentabilidade dos discentes e fidelizará os mesmos no curso.

A Unidade de Novos Negócios potencializará uma nova fatia de mercado "cursos técnicos", que após o término do mesmo haverá grande possibilidade dos egressos iniciarem um ensino superior.

\subsection{MODELO DE AÇÕES: atributos} de valor

Será apresentado a seguir o modelo das quatro ações, visando romper o trade-off "diferenciação-baixo custo" e criando uma nova curva de valor a partir dos quatro pontos em relação a lógica estratégica e o modelo de negócios (KIM e MAUBORGNE, 2005). Sabe-se que é uma tarefa desafiadora a elaboração desses pontos, porém, através desses é possível investigar intensamente todos os atributos de valor.

1- Eliminar: a fragmentação dos setores; a visão que pesquisa só é realizada através de bolsas da FAPEMIG e da UninCor; a percepção de que a extensão deverá ser ofertada apenas no espaço da Instituição.

2- Reduzir: evasão; inadimplência; prática pedagógica tradicional (behaviorista).

3- Elevar: qualidade, competitividade e inovação no nsino; empregabilidade; parcerias; bons resultados no ENADE e conexão dos alunos com mercado de trabalho.

4- Criar: a cultura da pesquisa; acrescer atividades de extensão e responsabilidade social; mais 
parcerias com as empresas/organizações; ensino diferenciado e competitivo; prática pedagógica inovadora e potencializar uma nova fatia de mercado oferecendo "cursos técnicos".

Será apresentado a seguir o gráfico elaborado por Alexandre Nogueira, colaborador da Hoper consultoria (2012), onde aponta a relação diferenciada sobre a curva de valor, realiza uma comparação genérica com a Universidade Anhanguera e as Instituições de

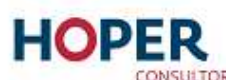

3. DIFERENCIADORES CURVA DE VALOR

Comparação genérica com concorrentes tradicionais.

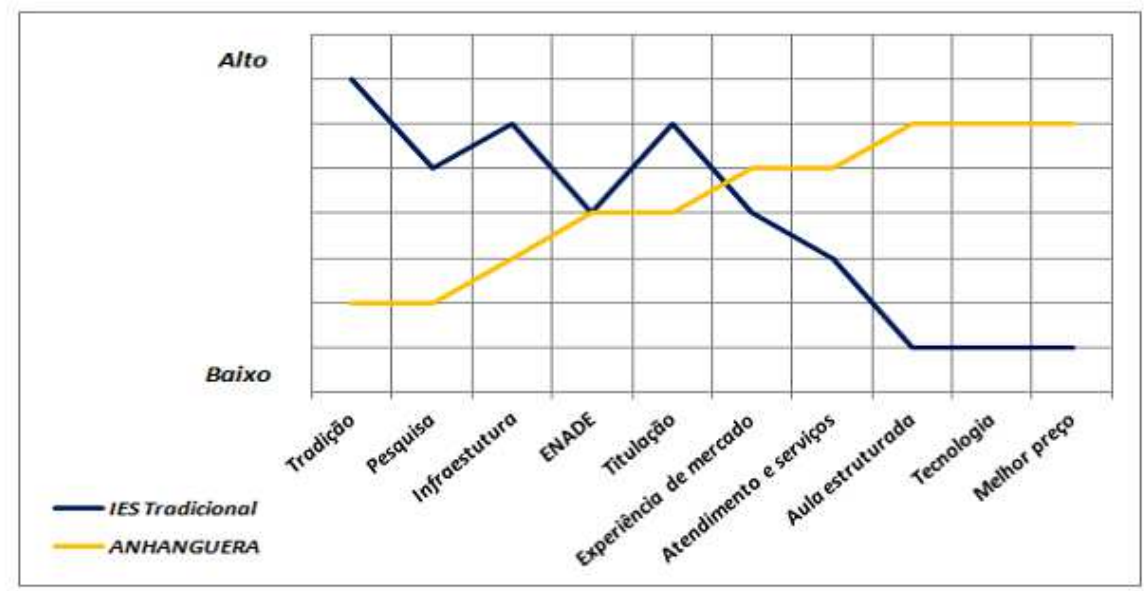

Figura 1 - Comparação de curva de valor entre concorrentes tradicionais e Anhanguera.

Pesquisa: será o grande foco através do Projeto Interdisciplinar PIN, onde aumentará o número de docentes com publicações, e colocará o aluno no centro do processo de aprendizagem. A pesquisa além de contribuir com as empresas/organizações parceiras contribuirá também com o desenvolvimento do aluno e professor e 
será um grande diferencial para a UninCor em relação aos seus concorrentes. empresas/organizações poderão financiar a pesquisa, o que contribuirá financeiramente com o aluno $\mathrm{e}$ consequentemente as questões de evasão e inadimplência. Será também intensificada a produção científica do professor/orientador, melhorando seu currículo e consequentemente a possibilidade de atingirmos as metas de publicações conforme critérios avaliativos do instrumento do MEC/INEP.

ENADE: através de estudos e pesquisas o aluno deixará de ser passivo, pois não se aprende na condição de objeto, assim o aprendizado será efetivo e deixará também de ser restrito apenas na sala de aula, consequentemente haverá mais estudo, autonomia, desejo, interação entre teoria e prática. O aluno será capaz de construir seu conhecimento, o que impactará nos resultados do ENADE e concursos, assim tornará os Cursos mais competitivos em relação aos das IES concorrentes. Com uma boa pontuação no ENADE o curso será isento de receber a comissão avaliativa do MEC/INEP, o que também contribuirá financeiramente com a UninCor.
Experiência de Mercado: o aluno em sua pesquisa poderá contar não somente com a orientação do professor, mas também com profissionais que estão na área de atuação, sendo possível reduzir o distanciamento entre a teoria estudada e a prática vivenciada. Serão oportunizadas mais parcerias, consequentemente mais atividades de extensão e maior faturamento. Aumentará a possibilidade de mais registros nas Atividades Complementares dos cursos além de maior divulgação e visibilidade da UninCor em relação aos funcionários das empresas conveniadas, comunidades externas e IES. Com o oferecimento dos cursos técnicos será também potencializada uma nova fatia do mercado.

Aula estruturada: com a proposta de aproveitar o PIN e realizar pesquisas nas empresas/organizações parceiras, o professor estudará mais, logo aprofundará seus conhecimentos, desta forma, deixará de ser maiêutico, "enchendo a cabeça" do aluno com transmissões apelativas e decadentes, deixará de dar respostas prontas, oferecer facilidades e encurtar raciocínio. Através desta proposta o professor motivará o aluno a estudar, pesquisar, reconstruir conhecimento pelas próprias mãos, orientando-o, 
desafiando-o, motivando-o e formando-

o como sujeito ativo no processo da aprendizagem.

\subsection{Proposta do trabalho de acordo} com a Análise Swot

Para a análise da criação da Unidade de Novos Negócios foi estudado a Análise S.W.O.T., uma vez que é uma ferramenta estrutural muito utilizada na análise do ambiente interno, facilitando a formulação de estratégias. Através dessa análise foi possível identificar as forças e fraquezas dos setores pesquisados, verificando as oportunidades e ameaças externas para os mesmos.

Estamos na era da informação, isso significa que o ambiente externo está mudando a cada dia, sendo necessário ter visão e competência para adaptar-se a estas mudanças, seja através do enfrentamento das ameaças ou aproveitamento das oportunidades. Da mesma forma que há necessidade de atentar para as mudanças do fator externo, há também a necessidade de observar o ambiente interno.

\section{Para Bicho et al}

A importância da identificação das forças e das fraquezas é particularmente importante para os aspectos mais controlados relacionados com os factores críticos de sucesso da organização em causa. É também importante referir que a consideração de uma determinada característica da empresa como força ou fraqueza é sempre relativa e potencialmente alterável, designadamente na medida em que se podem verificar ao longo do tempo alterações importantes ao nível da concorrência e do seu comportamento. A correcta listagem das suas forças e fraquezas dá à organização elementos importantes no que se refere à sua orientação estratégica, que tenderá naturalmente a tirar o maior partido possível das forças e a minorar ao máximo as fraquezas (2006, p.13).

De acordo com a citação anterior, percebe-se que o ambiente interno pode ser trabalhado pelos dirigentes da organização, uma vez que este é o resultado de estratégias de ação definidas por esses. Assim, quando se percebe um ponto forte na análise, deve-se controla-lo ainda mais; quando se percebe um ponto fraco, deve-se agir para controla-lo ou, pelo menos, minimizar seu efeito. 

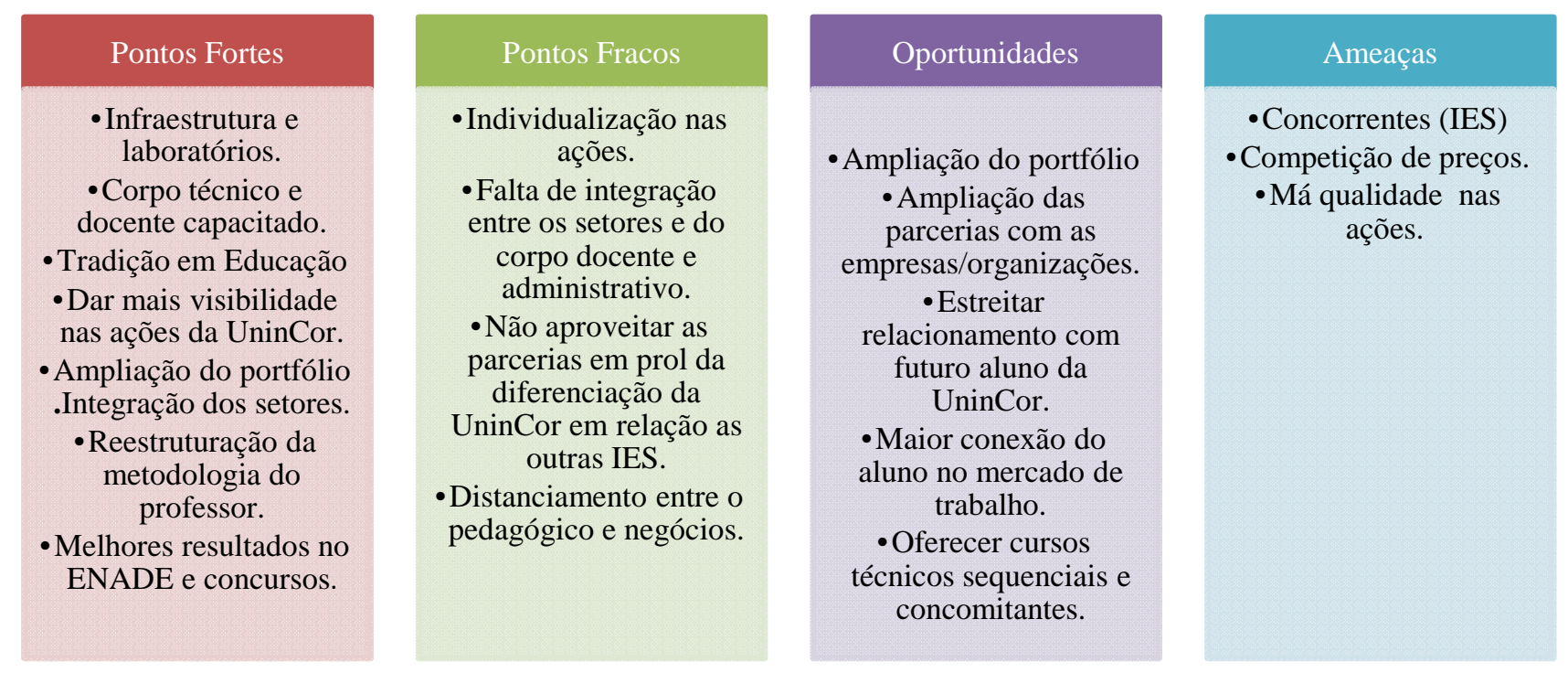

Figura 2 - Identificação das forças e das fraquezas da UninCor.

Para Romaniello et al ([200?], p.5) a Análise SWOT é uma das ferramentas mais comuns na análise estratégica. É a análise interna-externa, que se dá em quatro passos:

Passo 1: Analisar o ambiente interno da organização, identificando seus pontos fortes e seus pontos fracos.

Passo 2: Analisar o ambiente externo da organização, identificando suas oportunidades e ameaças.

Passo 3: Combinar (1) os pontos fortes com as oportunidades, (2) os pontos fracos com as ameaças, (3) pontos fortes com as ameaças e (4) os pontos fracos com as oportunidades.

Passo 4: Desenvolver estratégias para essas combinações que pareçam ser de grande importância para a organização. A maioria das organizações dá prioridade, em primeiro lugar, às estratégias que envolvem a combinação de pontos fortes com oportunidades; em segundo lugar dá prioridade às estratégias que envolvem combinação de pontos fracos e ameaças. A chave de tudo é explorar oportunidades em que seja forte e defender-se das ameaças em que a organização possui pontos fracos.

Através da análise de SWOT é possível equilibrar os pontos fortes e fracos internos da instituição, além de visualizar as oportunidades e riscos que o ambiente externo apresenta.

\subsection{Análise de Porter - modelo das cinco forças em relação a proposta de criação da Unidade de Novos Negócios}

Este modelo de análise foi desenvolvido por Michael Porter, onde estruturou um estudo voltado para a empresa e o meio onde está inserida, apontando as principais variáveis e os seus efeitos sobre toda a organização. Essa análise facilita a elaboração de estratégias mais eficientes e mais sólidas.

Para Saraiva et al (2007, p.12) "dentro destas cinco forças de Porter, pode-se 
notar a preocupação com toda a organização, cada departamento é importante, o mercado é analisado constantemente, há espaço para analisar clientes, fornecedores, concorrentes, as novas empresas e a rivalidade".

Neste sentido, serão apresentadas a seguir as cinco forças de Porter.

Concorrentes: muito acirrada através de empresas/instituições conhecidas como: SENAC, SENAI, Microlins, Dom Cabral, FGV, Entheos, LFG, UNIS entre outras.

Clientes: Empresas/organizações e comunidade interna e externa. Devido a grande demanda de empresa ofertantes os clientes estão utilizando da pratica de leilão de preços.

Fornecedores: Pró-reitoria de Pósgraduação, pesquisa e extensão, Próreitoria de Graduação e Assuntos Acadêmicos, alunos e escolas parceiras.

Novos concorrentes: Instituições que atuavam somente nos grandes centros estão migrando para o interior oferecer seus serviços.

Produtos substitutos: Interassat.

\subsection{Análise de Pest}

O objetivo do trabalho foi também estruturado tendo como base a análise de PEST, fazendo a análise dos fatores ambientais do marketing em relação criação da Unidade de Novos Negócios da UninCor, veremos a seguir as análises.

I- Fatores ambientais internos:

- A Unidade de Novos Negócios precisará envolver/inserir os colaboradores, o corpo docente e discente dos vários cursos em seus serviços, pois a UninCor possui quadro de profissionais que aliam a experiência técnica e acadêmica.

- A Unidade de Novos Negócios necessitará ocupar um espaço físico estratégico na Instituição, ou seja, que possa ser visualizado e de fácil acesso a comunidade interna e externa.

- A extensão precisa ser mais agressiva em suas ações, fazendo parcerias com empresas locais e regionais.

- A UninCor sendo uma universidade, tem a exigência da pesquisa, porém continua tímida em relação a produções, com a criação desta Unidade o setor da pesquisa terá mais 
visibilidade e importância

no desenvolvimento

acadêmico dos alunos,

sendo capaz de abranger

um número maior de

discentes e docentes e ser

mais agressivo em relação

as IES concorrentes.

II- Fatores micro-ambientais:

- Clientes externos: organizações, empresas da região e comunidade.

- Agentes e distribuidores: Pró-reitoria de Pósgraduação, Pesquisa e Extensão e Pró-reitoria de Graduação e Assuntos Acadêmicos.

- Fornecedores: professores, alunos e colaboradores da UninCor.

- Competição: SENAC, SENAI, Microlins, Dom Cabral, FGV, Entheos, LFG, UNIS entre outras.

III- Fatores macro-ambientais

3.1 Fatores Políticos:

- alterações frequentes na Regulamentação dos Instrumentos de Avaliação do MEC/INEP;
- instabilidade nas Legislações Educacionais;

- fragilidade na política;

- incentivo do governo aos cursos técnicos.

3.2 Fator Econômico:

- influencia do mercado cafeeiro;

- baixa renda per capta do público alvo;

- elevado custo de manutenção do capital humano para adequar com a Legislação Educacional;

- crise econômica;

- recessão da industria.

\subsection{Fator Social}

- área de desenvolvimento humano;

- status da formação acadêmica (adquirir uma formação profissional);

- perspectiva de melhoria salarial X formação;

- carência do capital humano qualificado $\mathrm{X}$ exigência do mercado;

- visão de ascensão social após uma formação profissional; 
- resistência das empresas a novas tecnologias de ensino.

\subsection{Fator Tecnológico}

- infraestrutura de telecomunicação influenciável;

- região industrializada tendo base tecnológica.

- massificação do acesso da informação através de tablets, celulares e outros;

- Ensino EAD.

Para a efetivação desta proposta será necessário ter visão pedagógica e de mercado, competência na elaboração e efetivação das ações, planejamento dos recursos e elaboração de plano de ação, esses são alguns passos da estratégia competitiva para que ocorra mudança.

\section{CONSIDERAÇÕES FINAIS}

A proposta de criação da Unidade de Novos Negócios vem de encontro com as necessidades atuais de mercado e atendimento às questões pedagógicas. Adotará em seu portfólio cursos diversos de extensão, cursos técnicos, pesquisas, consultoria e demais atividades, atendendo as demandas externas e interna, além de caracterizar um diferencial em relação as Instituições de Ensino concorrentes.

Com a criação dessa Unidade haverá necessidade de reinventar a organização corporativa da Pró-reitoria de Pós-graduação, Pesquisa e Extensão, sem acréscimo de capital humano e sim adequação de colaboradores de acordo com o perfil necessário.

Sabe-se que a Unidade de Novos Negócios oportunizará a caminhada conjunta entre as propostas pedagógicas da UninCor, de acordo com o PDI, PPI e integração dos diversos cursos de graduação. Ocorrerá enriquecimento pedagógico e oportunizará ao discente ter uma nova visão entre pesquisa, extensão, responsabilidade social, consultoria e a possibilidade da realização da junção entre teoria estudada em sala de aula com a prática vivenciada nas empresas/organizações.

Com o aumento significativo de IES na região, a criação desta Unidade de Negócios em parceria com empresas/organizações aumentará a visibilidade da UninCor diante a comunidade externa e valorização da comunidade interna. 


\section{REFERÊNCIAS}

BICHO, Leandro et al. Modelo de Porter

e Análise Swot - Estratégias de negócio.

Coimbra: Instituto Politécnico de

Coimbra, 2006. Disponível em:

<http://pt.scribd.com/doc/31449684/Mode

lo-de-Porter-e-Analise-de-Swot $>$.

Acessado em: 12 abril. 2013.

DEMO, Pedro. Professor do futuro e reconstrução do conhecimento. 3.ed.

Petrópolis: Vozes, 2005.

NOGUEIRA, Alexandre Gonçalves.

Estratégias Competitivas para Instituições de Ensino. Foz do Iguaçu: HOPER, Consultoria, 2012.

KIM, W. Chan e MAUBORGNE, Renée. A Estratégia do Oceano Azul: como criar novos mercados e tornar a concorrência irrelevante. 13.ed. Rio de Janeiro: Campus, 2005.

ROMANIELLO, Marcelo Márcio et al. Diagnóstico do ambiente organizacional e as técnicas de prospecção do futuro. Alfenas: Unifenas Campus C.P, 200?.

SARAIVA, Ana Catarina Paulo et al. Estratégia nas Organizações. Coimbra: Instituto Politécnico de Coimbra, 2007. 